\title{
Perioperative haemostatic management of patients with FXI deficiency: A single center retrospective study
}

\section{SAINT-Lues universitiaire

C. Capot $^{1}$, C. Hermans ${ }^{1}$, F. Veyckemans ${ }^{2}$, T. Pirotte ${ }^{1}$, N. Magasich - Airola ${ }^{1}$, C. Prégardien ${ }^{1}$

${ }^{1}$ Cliniques Universitaires Saint-Luc - Brussels (Belgium), ${ }^{2}$ Hôpital Jeanne de Flandre, Centre Hospitalier Régional Universitaire de Lille - Lille (France)

\section{Background and goal of the study}

Factor XI (FXI) deficiency is a rare inherited bleeding disorder characterized by bleeding manifestations of variable severity not correlated with the baseline FXI:Act. The aim of this study was to evaluate the perioperative management of patients with FXI deficiency. We investigated haemorrhagic complications according to the surgery and the applied prophylactic measures. This study has been approved by our Ethical Committee.

\section{Materials and methods}

Medical files of patients with FXI deficiency diagnosed at Cliniques Universitaires Saint-Luc, Brussels, Belgium between 2005 and 2017 (56) were analyzed. All haemostatic challenges that the patients underwent before and after diagnosis were analyzed retrospectively.

\section{Results and discussion}

- 56 patients : 19 patients with mild, 30 with a moderate and 7 with a severe deficiency

- 21 (38\%) patients: associated haemostatic disorder

- 37 patients $(66 \%)$ : prolonged APTT

- A total of 112 surgeries in 56 patients were analyzed

- Prior to diagnosis : 77 surgeries in 31 patients :

- 31 procedures $(40 \%)$ : excessive bleeding

- $90 \%$ : sites with high fibrinolytic activity

- No significant difference in FXI:Act between bleeders and non-bleeders $(P=0.62)$

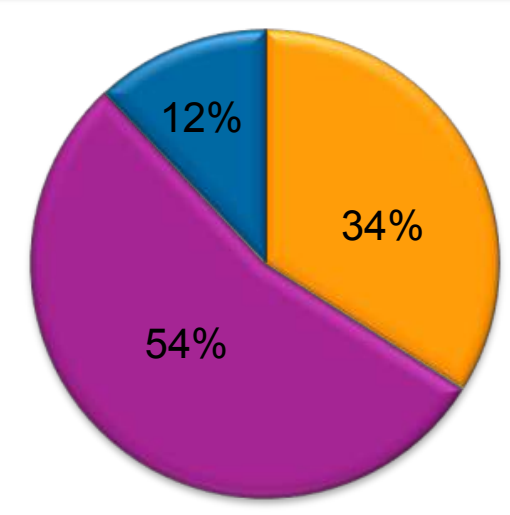

Minor deficiency (FXI : 50-70\%)

Moderate deficiency (FXI : 15-49\%)

Severe deficiency (FXI<15\%)

Fig. 1 : Severity of FXI-deficiency in patient population
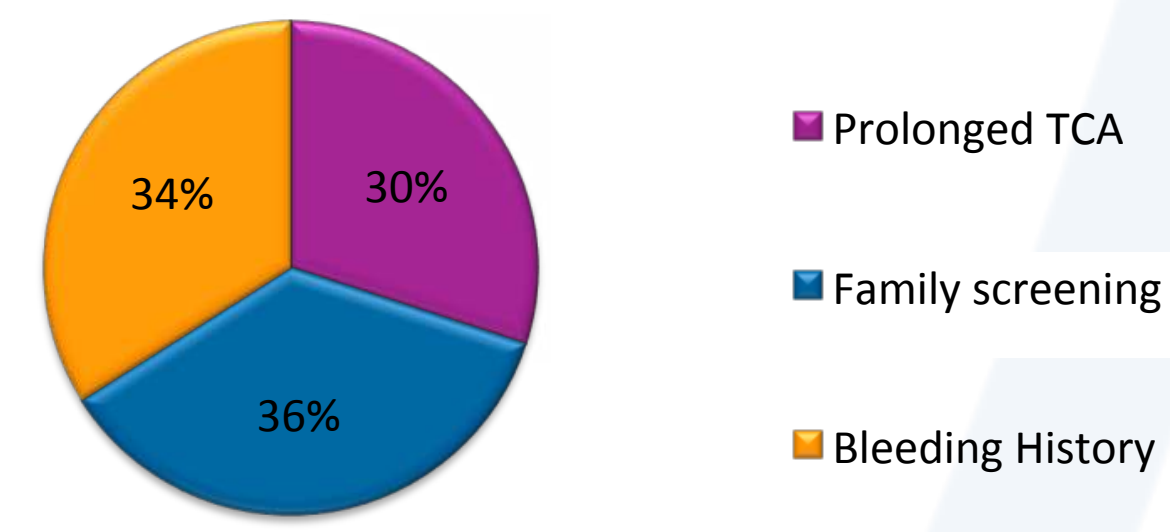

Fig. 2 : Reasons for diagnosis

- After diagnosis : 35 surgeries in 31 patients

- 31/35 surgeries performed with prophylactic treatment : Tranexamic Acid $(n=27)$ or in association with Fresh Frozen Plasma $(n=4)$

- 5 procedures $(14 \%)$ : haemorrhagic complication treated with FFP

\section{- 2 surgical revision \\ - 2 RBC transfusion}

- $60 \%(3 / 5)$ :sites with high fibrinolytic activity

○ $40 \%(n=2)$ : associated haemostatic disorder

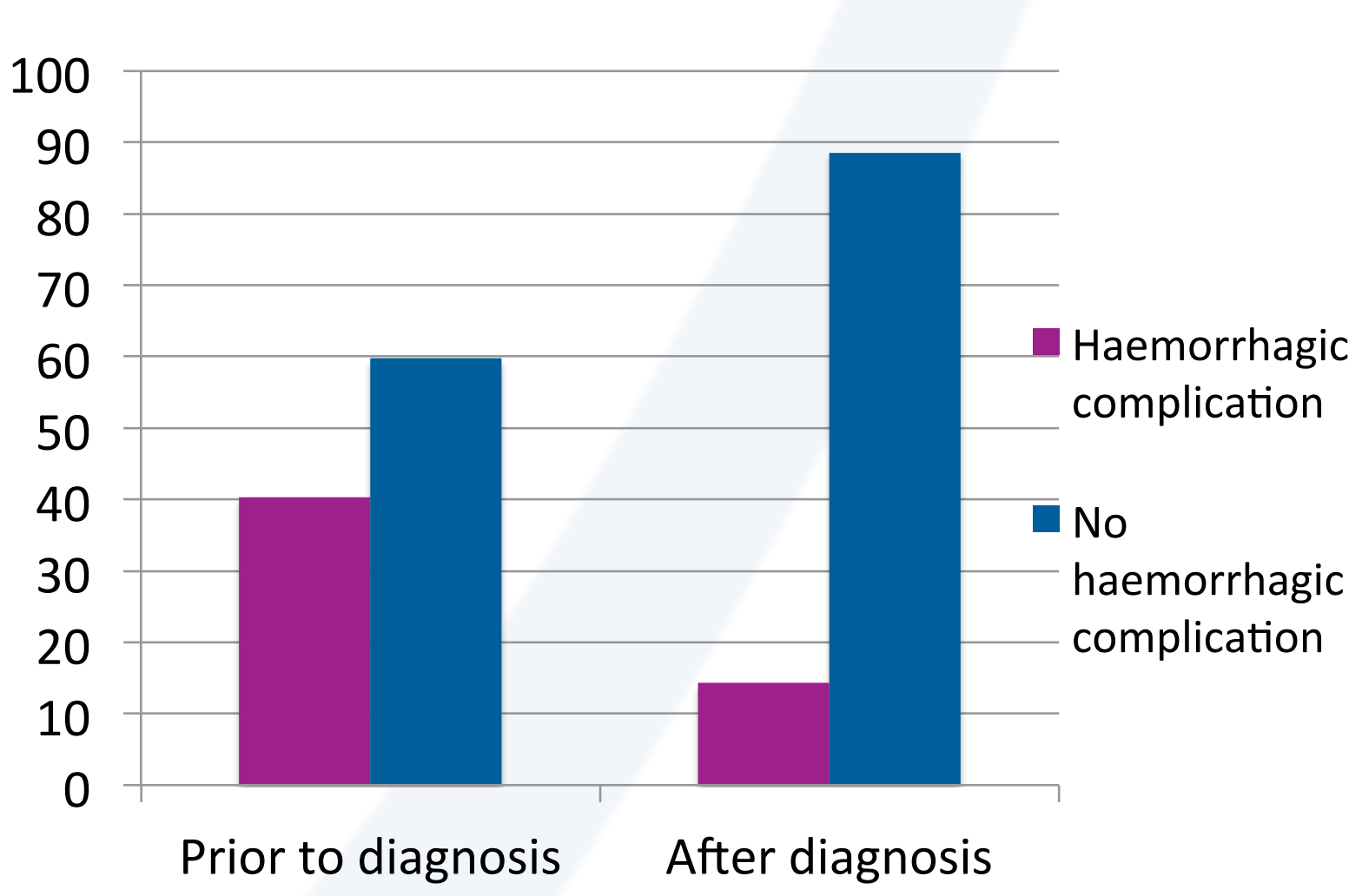

\section{Conclusions}

Patients with FXI deficiency may present variable bleeding risks not correlated with FXI:Act. Optimal perioperative haemostatic management requires attention to the bleeding tendency, the nature and the site of the procedure, and the presence of associated haemostatic disorders. Prophylactic treatment with TA is certainly needed to reduce the risk of bleeding complications. In case of excessive bleeding, treatment should include FFP and/or FXI-concentrate.

\section{References}

(1)Peyvandi F, Palla R, Menegatti M, Siboni SM, Halimeh S, Faeser B et al. Coagulation factor activity and clinical bleeding severity in rare bleedidng disorders : results from the European Network of Rare Bleeding Disorders. J Thromb Haemost. 2012 ; 10 : 615-621.

(2) Peyvandi F, Menegatti M. Treatment of rare factor deficiencies in 2016. Hematology Am Soc Educ Program. 2016 Dec 2 ; 2016 (1) : 663-669. 